\title{
Reflexões Sobre Resiliência Econômica Regional: o cenário pós-desastre de Mariana (MG)
}

\author{
Fernanda Faria Silva \\ Universidade Federal de Ouro Preto - Ouro Preto - Minas Gerais - Brasil \\ Jordana Ferreira da Silva \\ Universidade Federal de Minas Gerais - Belo Horizonte - Minas Gerais - Brasil \\ Igor Santos Tupy \\ Universidade Federal de Viçosa - Viçosa - Minas Gerais - Brasil
}

\section{Resumo}

Em 2015, o rompimento da barragem de rejeitos de Fundão, da mineradora Samarco fez do município de Mariana (MG) o epicentro de uma catástrofe que atingiu várias esferas: econômica, social, ambiental e humana. Este artigo se debruça sobre a literatura de Resiliência Econômica Regional para analisar a capacidade de resiliência econômica de Mariana e dos 34 municípios mineiros também impactados pela tragédia. A hipótese principal é que as características estruturais de localidades dependentes de um setor-chave restringem a sua capacidade de resistir e se recuperar-se economicamente dos choques adversos. Para a análise empírica dos efeitos do rompimento da barragem sobre os municípios afetados, foi utilizado o indicador de resistência econômica proposto por Martin et al. (2016) e o método shift-share para identificar os principais fatores responsáveis pela redução do emprego nestas localidades. Os resultados mostraram que a especialização produtiva e, ainda, o baixo dinamismo dos demais setores são fatores que comprometem a capacidade de recuperação pós-choque. Este trabalho se justifica por contribuir para a definição de políticas de apoio ao desenvolvimento local e indução à diversificação produtiva. As proposições feitas neste artigo apontam para a necessidade de ampliação da capacidade das famílias e empresas diversificarem suas fontes de renda, investirem nas relações sociais, manterem reservas de capital de diferentes tipos e desenvolverem competências de aprendizagem e de adaptação. E para o caso de Mariana, a vantagem competitiva no setor de turismo, a agricultura familiar e uma maior interação entre universidades e empresas podem gerar estratégias na indução da diversificação econômica.

Palavras-chave: Resiliência Econômica Regional. Especialização Produtiva. Mineração. Desastre Ambiental. Mariana (Brasil). 
Reflections on Regional Economic Resilience: the post-disaster scenario in Mariana (MG)

\begin{abstract}
In 2005, the rupture of the mining waste dam of the Samarco company made the municipality of Mariana (MG) the epicenter of a catastrophe that reached several spheres: economic, social, environmental and human. This article focuses on the literature on Regional Economic Resilience in order to analyze the economic resilience capacity of Mariana and the 34 municipalities also impacted by the tragedy. The main hypothesis is that the structural characteristics of localities that depend on a main-sector restrict their ability to resist and recover economically from adverse shocks. For the empirical analysis, the economic resistance indicator proposed by Martin et al. (2016) and the shift-share method was used in order to identify the main factors responsible for the reduction of employment in these localities. The results showed that the productive specialization and the low dynamism of the other sectors are factors that compromise the capacity of recovery after the shocks. Even this work is justified for contributing to the definition of policies to support local development and induction of productive diversification. The proposals made in this article point to the need to expand the capacity of families and companies to diversify their sources of income, invest in social relations, maintain capital reserves of different types and develop learning and adaptation skills. In the case of Mariana, the competitive advantage in the tourism sector, family farming and more interaction between universities and companies can generate strategies in the induction of economic diversification.
\end{abstract}

Keywords: Regional Economic Resilience. Productive Specialization. Mining. Environmental disaster. Mariana (Brazil).

\title{
Reflexiones sobre resiliencia económica regional: el escenario posterior al desastre en Mariana (MG)
}

\section{Resumen}

En 2015, la ruptura de la represa de desechos de minería de la empresa Samarco hizo del municipio de Mariana (MG) el epicentro de una catástrofe que alcanzó varias esferas: económica, social, ambiental y humana. Este artículo se centra en la literatura de Resiliencia Económica Regional para analizar la capacidad de resiliencia económica de Mariana y de los 34 municipios mineros también impactados por la tragedia. La hipótesis principal es que las características estructurales de localidades dependientes de un sector clave restringen su capacidad de resistir y recuperarse económicamente de los choques adversos. Para el análisis empírico se utilizó el indicador de resistencia económica propuesto por Martin et al. (2016) y el método shift-share para identificar los principales factores responsables de la reducción del empleo en estas localidades. Los resultados mostraron que la especialización productiva y el bajo dinamismo de los demás sectores son factores que comprometen la capacidad de recuperación después de los choques. Este trabajo se justifica por contribuir a la definición de políticas de apoyo al desarrollo local e inducción a la diversificación productiva. Las proposiciones hechas en este artículo apuntan a la necesidad de ampliar la capacidad de las familias y empresas de diversificar sus fuentes de renta, invertir en las relaciones sociales, mantener reservas de capital de diferentes tipos y desarrollar competencias de aprendizaje y de adaptación. Para el caso de Mariana, la ventaja competitiva en el sector del turismo, la agricultura familiar y más interacción entre universidades y empresas pueden generar estrategias en la inducción de la diversificación económica.

Palabras clave: resiliencia económica regional. Especialización productiva. Minería. Desastre ambiental. Mariana (Brasil).

\section{Introdução}


Os trabalhos envolvendo a temática da resiliência regional (regional resilience) são relativamente recentes na literatura econômica, sobretudo no Brasil onde, em geral, esses estudos têm sido desenvolvidos por um grupo ainda restrito de pesquisadores, com enfoque voltado para o entendimento dos impactos regionais da última crise financeira mundial (TUPY, 2015; TUPY, CROCCO e SILVA, 2018). No âmbito internacional, a literatura sobre resiliência econômica já está mais consolidada e tem se propagado graças aos estudos voltados para a área de geografia econômica e temas regionais e urbanos (EVENHUIS, 2017; DI CARO e FRATESI, 2018).

Em geral, a noção de resiliência regional se refere à habilidade de uma região em antecipar, se preparar, responder e recuperar-se de choques e distúrbios (FOSTER, 2007; BRIGUGLIO et al., 2009). O aumento do interesse pelo tema se justifica graças à eminência de grandes desastres ambientais que afligiram várias comunidades em diferentes partes do mundo e a rapidez com que as populações afetadas se recuperaram de tais choques (MARTIN, 2012). Para além desse aspecto, a emergência desse tema nos estudos regionais tem sido impulsionada pelo o interesse no desenvolvimento de noções e modelos de resiliência em outras áreas; no reconhecimento de que grandes choques podem exercer influência sobre a forma como as economias mudam ao longo do tempo; e, por fim, pela crise financeira global, iniciada em 2007 ( MARTIN et al., 2016; DUBÈ e POLĖSE, 2014;DORAN e FINGLETON, 2013; MARTIN, 2012; FINGLETON et al., 2012; PIKE et al., 2010; SIMMIE e MARTIN, 2010; PENDALL et al., 2010; CHRISTOPHERSON et al., 2010).

O entendimento da capacidade de resiliência econômica regional exige a compreensão das limitações econômicas e estruturais de uma região e como estas afetam na sua capacidade de reconversão. Assim, esse termo recupera e atualiza uma discussão bastante eminente nos autores da temática de desenvolvimento econômico dos anos 1960, em especial, os que questionavam os pressupostos de equilíbrio e estabilidade dos sistemas econômicos e sociais.

Myrdal (1960, p. 28), por exemplo, defendia que o 'sistema social' não realiza a auto estabilização automática pois este não se move espontaneamente na direção de um estado de equilíbrio. Segundo este autor, em virtude da causação circular, o processo social tende a tornar-se acumulativo, portanto, um choque exógeno, por si só, pode não estabilizar o sistema. A nova posição de equilíbrio não será resultado de forças do sistema, a menos que se tenham interferências políticas planejadas.

Em uma discussão mais contemporânea, Martin e Sunley (2015) evidenciam que choques recessivos podem causar mudanças estruturais e funcionais significativas, causando deslocamentos permanentes na capacidade produtiva de uma região, alterando a sua trajetória de crescimento. Uma recessão profunda pode resultar no fechamento de firmas e postos de emprego locais que leve ao colapso da base produtiva de uma região e do seu crescimento potencial. Ou, ainda, o fechamento de um grande empregador local pode levar à falência outras empresas pertencentes às suas cadeias de oferta local e das firmas de suporte.

Elementos como esses suscitam preocupações legítimas quanto ao caso de Mariana, município mineiro que ficou mundialmente conhecido pelo rompimento abrupto da barragem do Fundão, em novembro de 2015. Por isso, assim como no trabalho de Dubè e Polèse (2014), a preocupação deste artigo não será discutir os conceitos multidisciplinares do termo 'resiliência', mas, sim, a partir de um viés 
econômico, sugerir uma discussão teórica seguida de uma medida para analisar a capacidade de resiliência deste município frente a outros, de perfil econômico semelhante e que também foram atingidos ao longo do percurso do Rio Doce.

Desde o rompimento da Barragem de Fundão - de propriedade da mineradora Samarco - a região de Mariana tem convivido com o agravamento de problemas que, até então, eram menos recorrentes, tais como aumento do desemprego, baixo dinamismo do comércio local, queda na arrecadação tributária e, em especial, das contribuições, tendo as Compensações Financeiras pela Exploração de Recursos Minerais (CFEM) como a mais representativa (SILVA et al., 2017). Estas autoras alegam que a intensa interdependência setorial, típica de uma cidade com alta especialização produtiva, faz com que um impacto da magnitude da queda de uma barragem comprometa não somente a dinâmica mineradora da região, mas também, as atividades complementares diretas (infraestrutura, máquinas e equipamentos) e indiretamente relacionadas a esse setor (comércio e serviços).

O objeto de estudo deste trabalho é o município de Mariana, que já fulgurou como um dos maiores produtos per capitas de Minas Gerais ${ }^{1}$. De acordo com Silva (2018), a intensiva especialização marianense na atividade extrativa mineral não foi capaz de promover maior desconcentração de renda, diversificação produtiva e melhores condições de ampliar a capacidade de resistência frente a choques recessivos, tornando-o vulnerável aos choques adversos que atingem o setor de mineração.

A hipótese principal deste artigo é que as características estruturais deste município (mapeadas na segunda parte deste artigo) restringem a sua capacidade de resistir e se recuperar-se economicamente dos choques adversos, especialmente após o rompimento da barragem do Fundão. Com esta análise busca-se compreender as restrições intrínsecas a um município caracteristicamente minerador e apreender de que forma a especialização produtiva por si só pode ser um entrave ao aumento da resiliência econômica da região, interferindo na sua capacidade de reconversão econômica (SILVA et al., 2017; SILVA, 2018).

Ressalta-se que entender a baixa capacidade de resiliência e de reconversão econômica do munícipio de Mariana diante de um episódio relativamente recente não é trivial e pode ser considerado um problema de difícil aferição. Torna-se difícil dissociar o que é efeito da dinâmica econômica no período anterior (comprometida pela crise financeira de 2007-2008, seguida pela desaceleração econômica em vários países importadores de minério brasileiro); pelo impacto do decrescimento econômico chinês, bem como o preço do minério de ferro no mercado internacional de commodities, já em queda. Além das próprias características da sua especialização produtiva, com suas limitações estruturais e alta dependência do ciclo econômico. Soma-se a estes fatores, a própria restrição de dados mais atualizados que permitam traçar comparações dos cenários anterior e posterior ao rompimento da barragem.

Portanto, esse trabalho se defronta, ainda, com um cenário pós-choque relativamente recente e em transformação, estando, por isso, susceptível às novas

\footnotetext{
${ }^{1}$ De acordo com o Relatório do Centro de Estatística e Informações da Fundação João Pinheiro, em 2011, Mariana representava uma das maiores mudanças no ranking de municípios mineiros com maior PIB, tendo ampliado a participação da indústria extrativa a partir de 2010, passando de $25^{\circ}$ em 2009 para $12^{\circ}$ em 2010 e $10^{\circ}$ em 2011. Disponível em: http://fjp.mg.gov.br/index.php/docman/cei/pib/pibmunicipais/212-informativo-pib-municipios-mg-2011/file. Acesso em dezembro de 2018.
} 
condições de mudanças. No entanto, mesmo diante de tais limitações, esse artigo se justifica por tentar contribuir com uma discussão teórica e propositiva importante para que tanto o setor público quanto privado organize novas estratégias de planejamento para indução do crescimento econômico de Mariana, de forma a tornálo econômico e socialmente mais resiliente, o que passa pela definição de estratégias de diversificação produtiva a partir de suas vantagens locacionais, como, por exemplo, pela valorização de características históricas, culturais e de patrimônio.

\section{Características estruturais e entraves econômicos - as especificidades do município de Mariana}

Mariana integra o Território de Desenvolvimento Metropolitano e se situa na Vertente Sul da Serra do Espinhaço, no Quadrilátero Ferrífero mineiro. A mineração tem se expandindo no território local desde a década de 1970. A Mina de Germano foi construída pela Samarco Mineração S.A (joint venture da Vale e da angloaustraliana BHP Billiton), alterando toda a estrutura local. Com ela surgiram as pressões do crescimento da populacional, principalmente advindas dos fluxos migratórios em busca de empregos; novas demandas às firmas locais (comércio e serviços); pressão pela ampliação da qualidade e escala na oferta de infraestrutura urbana e de transportes, pressões sobre o meio ambiente e por maior regulamentação, alteração no modo de vida da população originária para dar conta de todas estas transformações em seu local.

Nesse aspecto, os conceitos de backwash effects (ou efeitos regressivos) e spread effects (efeitos propulsores), desenvolvidos por Myrdal (1960) são fundamentais para esta análise. No primeiro caso, movimentos de mão de obra, capital, bens e serviços não impedem, por si só, que a região seja desigual. Estes fatores são parte do processo acumulativo e se desenvolvem de forma top-down, ou seja, das regiões mais para menos desenvolvidas, ficando as primeiras os efeitos positivos deste processo. Já os efeitos propulsores se propagam de forma centrífuga, ou seja, dos centros de expansão econômica para outras regiões. Podem, assim, atingir as localidades mais distantes, quando for do interesse comercial (por exemplo, para obtenção de matéria - prima com finalidade de abastecer as indústrias das regiões centrais).

Mariana recebeu um grande impulso econômico com a atividade mineradora (assim como outras localidades à sua volta). Esse município absorveu grande parte da mão de obra e dos recursos de outras localidades, intensificaram-se as pressões por melhorias na infraestrutura e nos serviços municipais (GONÇALVES, 2014; SILVA et al., 2017). Distritos e localidades vizinhas que não foram diretamente beneficiados pela atividade mineradora, tiveram sua dinâmica social e econômica polarizada pelo desempenho de Mariana (PASSOS et al., 2017).

Para se ter uma ideia da importância econômica da mineração para o município, de acordo com os dados do IBGE (2014), neste ano, a renda per capita municipal era cerca de $\mathrm{R} \$ 86.000,00$ (a maior entre os 35 municípios atingidos pelo rompimento da barragem do Fundão). De acordo com esta fonte, a composição setorial do Produto Interno Bruto marianense compunha-se de: 70\% de participação da indústria (vinculada a extração de minério de ferro); $25 \%$ do setor de serviços, 0,01\% pela agropecuária e o restante para administração pública (essa última, a responsável 
pelo maior número de ocupações e pelas melhores remunerações no ano em questão).

No que tange aos empregos formais, os dados da RAIS para 2018 informam que os setores que mais empregam são serviços, comércio e administração pública (figura 1). O setor terciário de Mariana é composto essencialmente por segmentos voltados para as atividades de consumo pessoal e domiciliar, com exigência de mão de obra pouco especializada (de menor qualificação) e de mais baixos salários: lojas de roupas e acessórios, lanchonetes, supermercados, bares e restaurantes, entre outros. Logo, de acordo com Silva et al. (2017) apresenta menor capacidade de gerar estímulos mais dinâmicos na economia do município, de reagir de forma contra cíclica frente ao esgotamento de ciclos de consumo ou mesmo reagir frente às consequências econômicas de choques adversos, como no caso do rompimento da barragem.

Figura 1. Distribuição do Emprego Formal por Setores em Mariana, 2014: Curva de Especialização

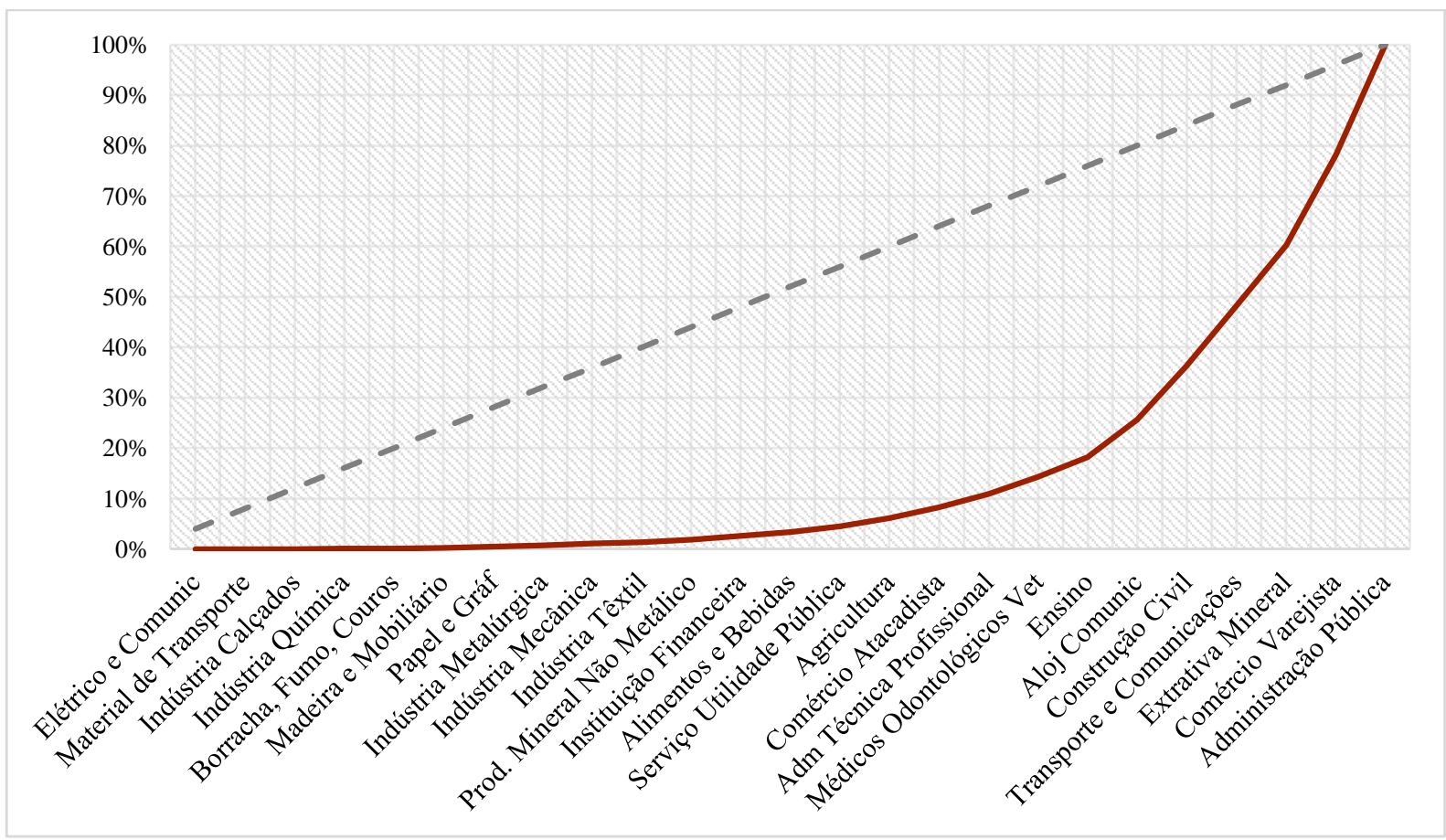

Fonte: Elaboração Própria com base na RAIS/ MTE (2018)

No que diz respeito à questão fiscal, o conhecimento do grau de dependência da arrecadação municipal sobre as receitas provenientes da extração mineral é uma necessidade para os municípios mineradores, assim como a forma de investir estes recursos - principalmente por conta da exauribilidade das jazidas e da grande flutuação do mercado de commodities (GONÇALVES, 2014). A figura 2 apresenta a evolução da arrecadação total do município com base nos dados extraídos do Portal da Transparência da Prefeitura de Mariana, disponíveis a partir de 2011, e o total de CFEM recolhida pelo município. Nota-se que, a queda no recolhimento da CFEM 
contribuiu para a queda da arrecadação total no município entre os anos de 2013 a 2017.

Figura 2. Evolução da Arrecadação Total e do Recolhimento da CFEM sobre a operação de Minério de Ferro, no Município de Mariana, 2011 - 2017

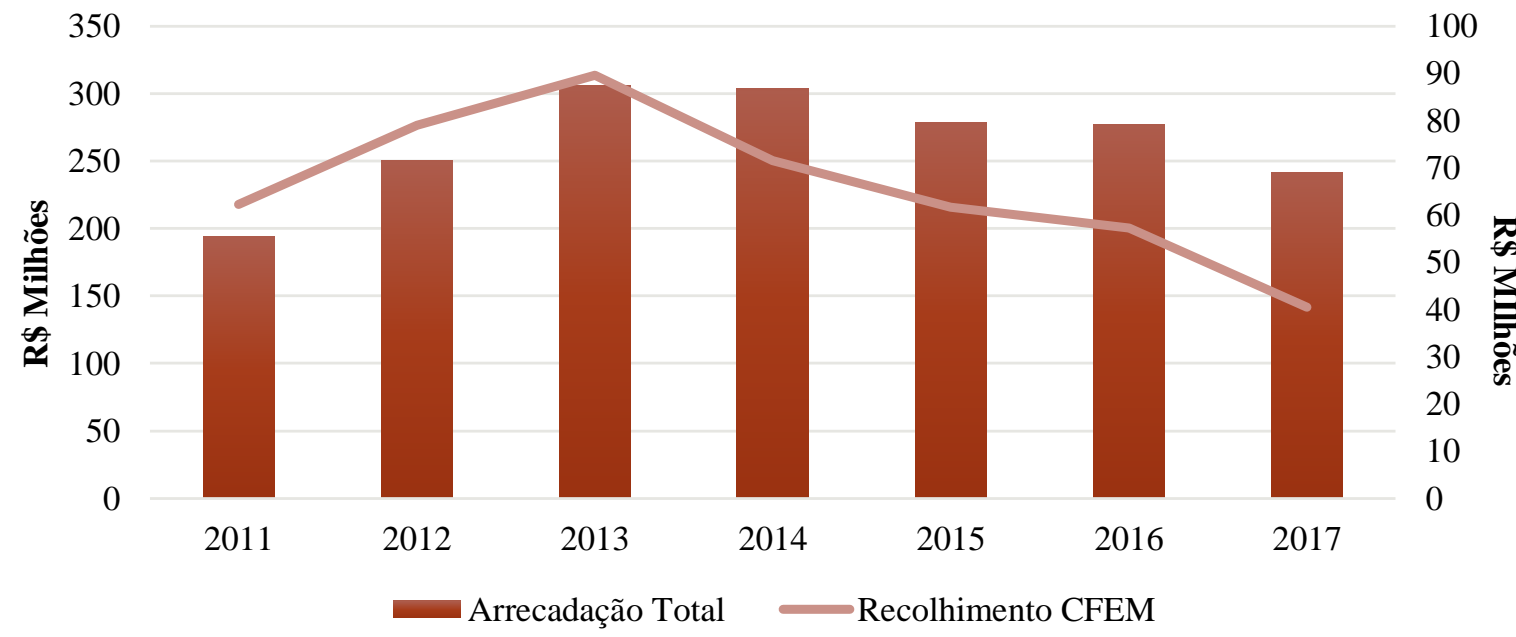

Fonte: Silva (2018).

O município, no entanto, restringiu a sua capacidade produtiva à atividade mineradora, imprimindo pouco esforço em termos de políticas de indução setoriais para outras modalidades. Assim, relegou-se a um segundo plano alternativas como a atividade de turismo ou mesmo de serviços mais complexos, aproveitando as externalidades positivas do conhecimento gerado pela presença de instituições como a Universidade Federal de Ouro Preto (seu capital humano e infraestrutura), a Fundação Gorceix, a proximidade geográfica com uma área estratégica e economicamente diversificada (tal como a região metropolitana de Belo Horizonte), entre outras vantagens locacionais e competitivas.

Ademais, a atividade mineradora tem uma lógica de acumulação peculiar. Segundo (PASSOS et al., 2017), organiza-se em um mercado concentrado, formado por grandes empresas (nacionais e estrangeiras) que imprimem grandes investimentos em reestruturação produtiva e melhorias de produtividade. No Brasil, em geral, os municípios mineradores se atêm à parte operacional do processo produtivo, sendo que a pesquisa e o desenvolvimento, bem como o conhecimento especializado são desenvolvidos em seus headquarters (grandes centros no Brasil ou em outros países).

No caso de Mariana, por exemplo, o conhecimento mais especializado, mais complexo, tampouco é internalizado no local. De acordo com o levantamento feito, a partir das 40 principais empresas que prestam serviços diversos ${ }^{2}$ para a Vale e a

\footnotetext{
2 Entre os serviços detectados, listam-se: infraestrutura e obras industriais: montagem eletromecânica, grandes reparos e manutenções em paradas programadas, comissionamento, partida e operação assistida, construção e montagem de dutos, obras de construção civil; gerenciamento de empreendimentos, compras e suprimentos de equipamentos e materiais; mineração; siderurgia; metalurgia; auditoria ambiental; logística; indústria química e tratamento de água.
} 
Samarco nessa região, SILVA et al. (2017) detectaram que nenhuma delas tinha a sede principal neste município - $64 \%$ estavam sediadas em Belo Horizonte (incluindo Nova Lima); e as demais em outras localidades do Espírito Santo (Vitória e Serra); São Paulo (capital e São Caetano do Sul), Rio de Janeiro, Maranhão, entre outros locais. De acordo com as autoras, este é um indício de como parte da renda gerada é pouco internalizada no município no qual a indústria está instalada, por isso, os vazamentos diretos (de renda, de lucros, de mão de obra mais qualificada e de salários) prejudica a interiorização da demanda agregada e a geração de novos investimentos.

Dessa forma, o que é internalizado no município minerador, guarda intrínseca relação de dependência intersetorial com esta atividade por parte do comércio, dos serviços e outras que, quando não são complementares à atividade extrativista, tem gerado efeitos de encadeamento menos intensos no estímulo à diversificação produtiva e de renda, o que melhoraria a condição de resiliência econômica do município. Corroborando com a discussão feita por Myrdal (1960), se as forças do mercado são regressivas, elas neutralizam qualquer ação das forças propulsoras. É o caso de localidades como Mariana, que não conseguem dinamizar os efeitos propulsores advindos com o boom da mineração, ficando bastante restritos à própria dinâmica do setor minerário, tornando a localidade menos resiliente às mudanças nas trajetórias de crescimento, e, com isso, dificultando a sua capacidade de recuperação econômica.

\section{Resiliência econômica e setores produtivos em Mariana (MG)}

A proposta empírica do trabalho é evidenciar o comportamento de variáveis socioeconômicas de Mariana, a fim de analisar como este município reagiu aos dois principais choques mais recentes (queda preço de commodities e o rompimento da barragem da Samarco). Como método de análise, pretende-se calcular indicadores para a avaliação dos efeitos dos choques e o comportamento do município em termos de resistência da atividade econômica.

A análise exploratória deste tópico baseia-se em abordagens contrafactuais, tendo como referência o desempenho da economia nacional no mesmo período. Partindo do artigo de Martin et al. (2016) e baseado num tipo de reação (resistência e recuperação) da economia nacional como um todo, espera-se que as localidades com perfil minerador tenham uma performance parecida, ou seja, que as variáveis reais contraiam (recessão) ou expandam (recuperação) à mesma taxa que a economia nacional. Martin et al. (2016) definem a mudança esperada no emprego em uma região $r$ em uma recessão ou recuperação, em $k$ períodos como:

$\left(\Delta E_{r}^{t+k}\right)^{e}=\sum_{i} g_{N}^{t+k} E_{i r}^{t}$

onde $\sum_{i} g_{N}^{t+k}$ é a taxa de contração (na recessão) ou expansão (na recuperação) do emprego nacional, e $E_{i r}^{t}$ é o emprego na indústria i na região r no tempo inicial $t$ (ano base), que é o ponto de viragem para a recessão ou a recuperação.

Para mensurar a resistência ou a recuperação de uma região o autor usa as seguintes equações, respectivamente: 
$\operatorname{Resis}_{r}=\frac{\left(\Delta E_{r}^{\text {Recessão }}\right)-\left(\Delta E_{r}^{\text {Recessão }}\right)^{\text {esperada }}}{\left(\Delta E_{r}^{\text {Recessão }}\right)^{\text {esperada }}}$

$\operatorname{Recup}_{r}=\frac{\left(\Delta E_{r}^{\text {Recuperação }}\right)-\left(\Delta E_{r}^{\text {Recuperaç̃o }}\right)^{\text {esperada }}}{\left(\Delta E_{r}^{\text {Recuperaçao }}\right)^{\text {esperada }}}$

As medidas das equações (2) e (3) são centradas em zero, por definição. Com isso, um valor positivo de Resis $_{r}$, por exemplo, indica que uma região é mais resistente à recessão, e por isso, seria menos afetada por uma crise em relação à economia nacional. $O$ resultado negativo significa que a região é menos resistente, portanto, seria mais afetada pela recessão.

Para que seja possível estabelecer um parâmetro sobre a capacidade de resiliência regional do município de Mariana, foram calculados os indicadores para os 35 mineiros atingidos pelo rompimento da Barragem de Fundão. De acordo com Silva et al. (2017), Silva (2018), todos os municípios atingidos, de Minas Gerais ao Espírito Santo 3 , tiveram prejuízos de toda a ordem: do ponto de vista econômico foram comprometidas suas infraestruturas urbana e rural, o abastecimento de água, a geração de energia elétrica e o desempenho de seus diversos setores, especialmente, agricultura, pecuária, pesca, turismo e comércio.

Somente em Mariana, de acordo com as informações obtidas junto ao Sistema Nacional de Emprego (SINE) durante o ano de 2016, 5.010 trabalhadores perderam seus postos de trabalho devido à paralisação da Samarco. Segundo consulta feita ao mesmo órgão, a taxa de desemprego de Mariana até abril de 2017 era de 24\% da população ativa. O resultado dos índices Resis para a variação do emprego entre os anos de 2014 e 2016 constam na Figura 3.

Os resultados do índice de Resistência para Mariana no período mostram que o município teve pior desempenho econômico que a economia nacional durante o período de crise.

\footnotetext{
${ }^{3}$ Segundo a Superintendência de Planejamento de Recursos Hídricos (2016) ao todo, Minas Gerais teve 35 municípios diretamente atingidos pelo rompimento da Barragem de Fundão (que podem ser observados na Figura 2). No estado do Espírito Santo, foram diretamente afetados os municípios de Linhares, São Mateus, Aracruz e Serra. Esta região é circundada pelo Rio Doce, compondo, assim, a chamada Calha do Rio Doce. De acordo com o mesmo documento desta Superintendência, no total, esta bacia compreende 225 municípios, cujos territórios estão total ou parcialmente nela inseridos, sendo 200 mineiros e 25 capixabas. São 209 sedes municipais localizadas no território da bacia, com uma população residente de aproximadamente 3,6 milhões de habitantes.
} 


\section{Figura 3. Índices de Resistência do Emprego Formal para os municípios atingidos}

em Minas Gerais, 2014-2016
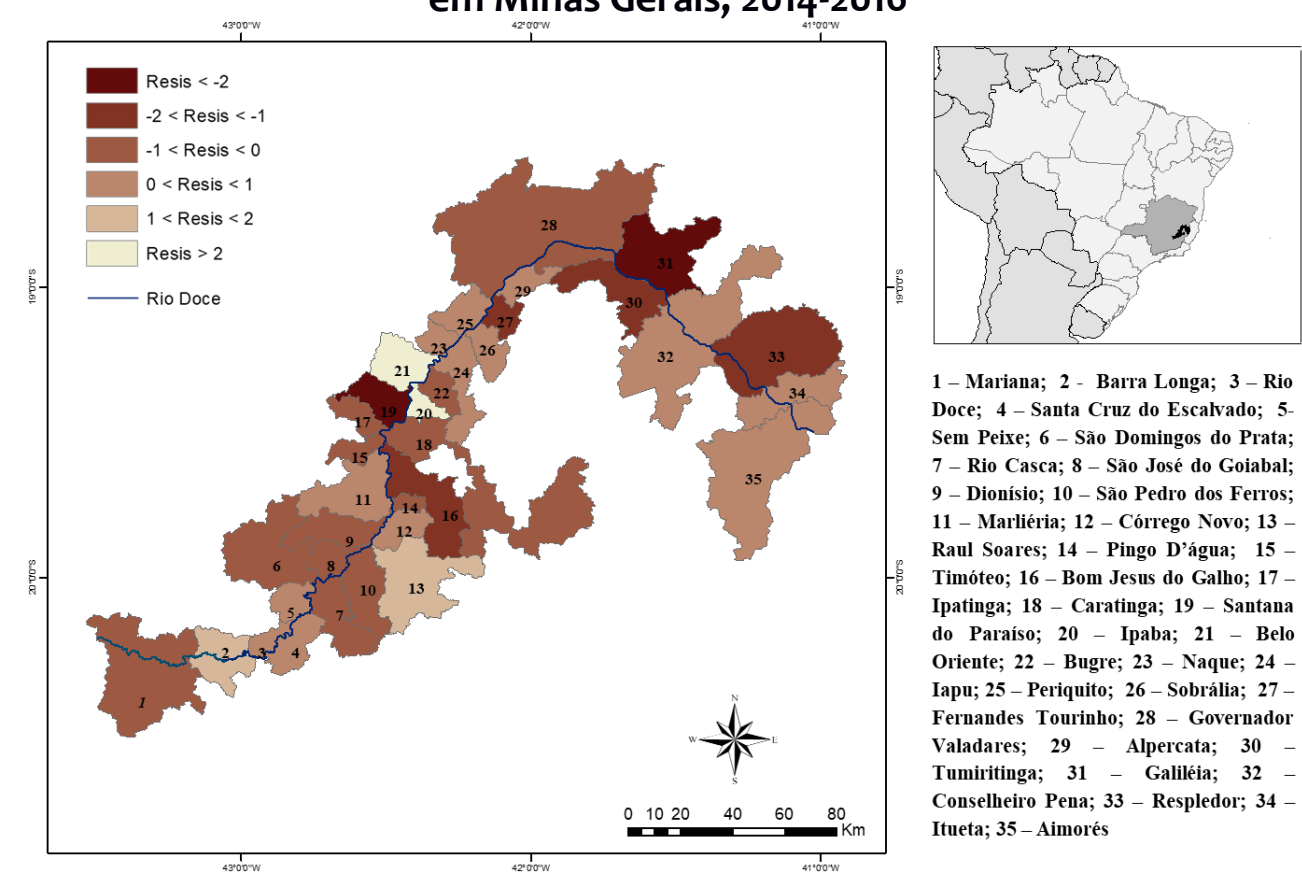

1 - Mariana; 2 - Barra Longa; 3 - Rio Doce; 4 - Santa Cruz do Escalvado; 5 Sem Peixe; 6 - São Domingos do Prata; 7 - Rio Casca; 8 - Sào José do Goiabal; 9 - Dionisio; 10 - São Pedro dos Ferros; 11 - Marliéria; 12 - Córrego Novo; 13 Raul Soares; 14 - Pingo D’água; 15 Timóteo; 16 - Bom Jesus do Galho; 17 Ipatinga; 18 - Caratinga; 19 - Santana do Paraíso; 20 - Ipaba; 21 - Belo Oriente; 22 - Bugre; 23 - Naque; 24 Iapu; 25 - Periquito; 26 - Sobrália; 27 Fernandes Tourinho; 28 - Governador Valadares; 29 - Alpercata; 30 Tumiritinga; 31 - Galiléia; 32 Conselheiro Pena; 33 - Respledor; 34 Itueta; 35 - Aimorés

Fonte: Elaboração própria a partir dos dados da RAIS/MTE (2018).

O índice reflete o agravamento da situação do emprego que se verificou após a ocorrência do desastre, pois o choque da barragem do Fundão coincidiu com a ocorrência de uma grande recessão a nível nacional. Além disso, o próprio setor minerador vinha sedo duramente afetado pela queda nos preços das commodities. Portanto, o índice de resistência não permite captar apenas o efeito do desastre, em si, mas reflete em algum grau o agravamento da situação econômica dos municípios atingidos por ambos os choques.

A fim de depurar mais a análise, recorre-se à decomposição estruturaldiferencial para a variação no emprego local, o método shift-share. Análises de shiftshare vem sendo crescentemente utilizada nos estudos sobre resiliência regional (MARTIN et al., 2016, RAY et al., 2017, GIANNAKIS E BRUGGEMAN, 2017 e ÂNGULO et al., 2018). Com ela, busca-se identificar os principais fatores responsáveis pela redução do emprego no período. A variação do emprego é decomposta entre três componentes: Nacional (N), Estrutural (E) e Diferencial (D). O componente nacional deve refletir o papel da crise nacional na redução do emprego nessas localidades. $O$ componente estrutural (chamado de Mix Industrial), captura a redução que se deve ao desempenho a nível nacional dos setores nos quais o município é especializado (por exemplo, o efeito específico da queda nos preços das commodities). Finalmente, o efeito diferencial refere-se aos elementos particulares a cada local que levaram à queda no emprego, por exemplo, os efeitos do rompimento da barragem.

Propõe-se decompor a variação do emprego local em cada setor i entre dois períodos, $t$ e $k$ como:

$\Delta E_{i r}^{(t+k)}=E_{i r}^{(t+k)}-E_{i r}^{t}=N(t+k)+E(t+k)+D(t+k)$ 
O componente nacional reflete exatamente o quanto o emprego local em cada setor $\left(E_{i r}^{t}\right)$ teria se retraído se apenas a recessão nacional o afetasse, isto é, se tivesse variado na mesma taxa de desempenho nacional $\left(g_{N}^{t+k}\right)$. Utilizando a mesma notação que na equação (1),

$N(t+k)=\sum_{i} g_{N}^{t+k} E_{\text {ir }}^{t}$

Entretanto, cada setor, a nível nacional, teve uma taxa de crescimento ou queda específica, $g_{I}^{t+k}$. O componente estrutural considera então a diferença entre as taxas de variação da economia nacional e dos setores agregados. Com isso, analisase como o emprego local em cada setor teria se comportado caso siga a tendência da atividade a nível nacional.

$E(t+k)=\sum_{i}\left[g_{N}^{t+k}-g_{I}^{t+k}\right] E_{i r}^{t}$

Por fim, o componente diferencial considera a parcela da variação no emprego local em cada setor $g_{i r}^{t+k}$ que não pode ser explicada pelo comportamento agregado.

$D(t+k)=\sum_{i}\left[g_{I}^{t+k}-g_{i r}^{t+k}\right] E_{i r}^{t}$

Com isso, pode-se classificar as regiões em quatro categorias, conforme as dimensões estruturais e diferenciais. A primeira delas, categoria I, é composta por localidades em que tanto a dinâmica dos setores nos quais elas se especializam quanto elementos particulares a essa região contribuíram para reduzir o impacto da recessão a nível nacional.

Municípios classificados na categoria II tem padrão de especialização favorável, mas elementos específicos que atuaram no sentido de aprofundar a recessão. No caso III, embora os elementos particulares ao local tenham contribuído positivamente, a dinâmica setorial a nível nacional atuou de forma a aprofundar a recessão. O resultado sobre o emprego nos casos II e III vai depender das magnitudes de ambos os efeitos. Por fim, o caso IV é o pior deles, pois os elementos locais quanto ao padrão de especialização atuaram no sentido de aprofundar a recessão nacional.

A figura 4 mostra essa classificação para os municípios atingidos. Como pode ser visto, dentre os municípios atingidos, Mariana encontra-se no pior caso possível (no grupo IV), sendo possível inferir que a recessão, o padrão de especialização e os eventos que ocorreram localmente atuaram no sentido de deprimir o emprego local. Na maior parte dos municípios atingidos ocorre-se os grupos II ou IV, que indicam que, mesmo filtrando a situação nacional e estrutural, existem elementos locais que atuaram no sentido de aprofundar a queda no emprego. Os impactos do desastre inserem-se nesses elementos. 


\section{Figura 4. Classificação dos Municípios Conforme Taxonomia do Shift-Share}
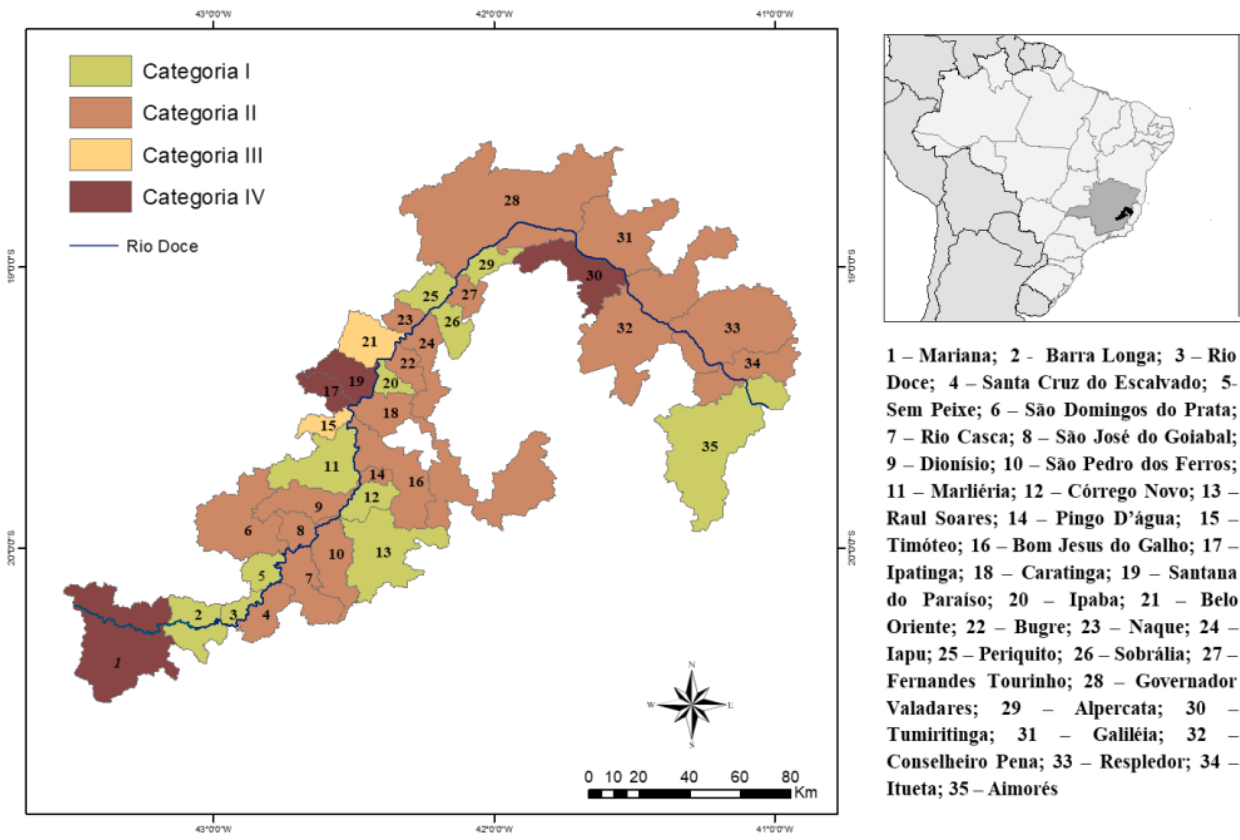

1 - Mariana; 2 - Barra Longa; 3 - Rio Doce; 4 - Santa Cruz do Escalvado; 5 Sem Peixe; 6 - São Domingos do Prata; 7 - Rì Casca; 8 - São José do Goiabal; 9 - Dionisio; 10 - São Pedro dos Ferros; 11 - Marliéria; 12 - Córrego Novo; 13 Raul Soares; 14 - Pingo D'água; 15 Timóteo; 16 - Bom Jesus do Galho; 17 Ipatinga; 18 - Caratinga; 19 - Santana do Paraiso; 20 - Ipaba; 21 - Belo Oriente; 22 - Bugre; 23 - Naque; 24 Iapu; 25 - Periquito; 26 - Sobrália; 27 Fernandes Tourinho; 28 - Governador Valadares; 29 - Alpercata; 30 Tumiritinga; 31 - Galiléia; 32 Conselheiro Pena; 33 - Respledor; 34 Itueta; 35 - Aimorés

Fonte: Elaboração Própria com base nos dados da RAIS/MTE (2018).

O método shift-share permite, ainda, decompor tais efeitos segundo setores de atividade. Mariana e Ipatinga classificam-se no grupo IV. Os resultados evidenciam que o setor extrativo mineral foi o principal responsável pela queda no emprego em Mariana, seguido do setor de transporte e comunicações. Em ambos os casos, o impacto específico do desastre é evidente.

No caso do setor extrativo mineral, todos os fatores contribuíram para uma queda da atividade no período. Corrobora-se que a queda da atividade minerária em Mariana acompanhou, de fato, a tendência da economia nacional e a do setor como um todo, o que possivelmente reflete a dinâmica do preço do minério. Contudo, esses fatores juntos não explicariam nem metade do comportamento do setor no período analisado. A maior responsabilidade pela queda na atividade se deve a fatores diferenciais, que para Mariana estão ligados ao desastre.

Calculou-se, também, os índices Resis com foco nas dinâmicas setoriais para o município de Mariana, com atenção particular a outros municípios como Caratinga, Governador Valadares, Ipatinga e Timóteo, os que mais se aproximam sob ponto de vista populacional, econômico e nível de desenvolvimento humano à realidade marianense, integrando um importante centro produtivo em Minas nos setores de extração mineral e metalurgia.

O resultado do cálculo dos indicadores de resiliência para os municípios supracitados pode ser visto no Anexo. Em primeiro lugar, é possível perceber que os setores comércio $(-1,14)$ e serviços $(-1,17)$ apresentaram, em média, os piores indicadores de resistência setorial, reforçando a hipótese que esses setores são os que mais sofrem com as relações intersetoriais em períodos de choques econômicos adversos. Os setores de construção civil, administração pública e serviços industriais de utilidade pública também apresentaram baixa resistência. 
No que tange à indústria de transformação $(-0,52)$, a dinâmica foi comprometida pelos impactos nas atividades da Usiminas, na região do Vale do Aço. O setor de extração mineral, apesar de apresentar baixa resistência, apresentou média de -0,19, sendo assim, é o setor mais resistente nos três anos observados (2013, 2015 e 2016). Isso pode estar relacionado à alta resistência do setor no ano de 2013 nos cinco municípios compensando, assim, a perda de resistência nos anos seguintes. Insta ressaltar que tendo em vista o papel central da atividade extrativa mineral para estes municípios, qualquer choque que afete este setor produtivo gera efeitos de desencadeamento nos demais que são complementares a esta atividade, o que ajuda a entender os baixos indicadores de resiliência aferidos na indústria de transformação, construção civil e, em parte, nos serviços.

Em contrapartida, o setor agropecuário, extrativo vegetal, caça e pesca $(-0,25)$ mostrou-se o segundo mais resistente. $O$ fato de ser mais resiliente não significa que a atividade agropecuária imprima dinamismo econômico a estes municípios. Ao contrário do que se esperava, a participação do setor agropecuário no PIB municipal em 2014 era pouco significativo, principalmente para os municípios de Ipatinga (0,02\%) e, Mariana (0,01\%).

Partindo para uma análise individual dos municípios, observamos que todos apresentaram queda de resistência no setor de extração mineral nos anos de 2015 e 2016, com exceção de Governador Valadares. Nele, com exceção da agropecuária, todos os setores tiveram perda de resistência em 2015 e 2016. Em Caratinga, vale destacar o desempenho positivo do setor de serviços no biênio 2015-2016, sendo assim, o único setor resistente no município no período analisado. Timóteo apresentou baixa resistência em todos os setores, mas o que chama a atenção é o baixo desempenho do setor de agropecuário que, diferentemente dos demais, registrou elevada vulnerabilidade no período em questão. Em Ipatinga, todos os setores apresentaram baixa resistência (exceto o setor de agropecuária). A indústria de transformação é a atividade principal da economia Ipatinguense (39,2\% do PIB local), com a produção de aços planos, seguida pelos serviços que geraram $60,8 \%$ do PIB do município em 2015 (FJP, 2017).

Uma parte significativa do entorno do Rio Doce teve um desempenho econômico bastante favorecido em decorrência da atividade industrial e, mais especificamente, da mineradora, que impulsionou outros setores como o de serviços vinculados à esta atividade. Devido a sua posição estratégica (entre o interior minerador do estado de Minas Gerais e os portos do estado do Espírito Santo), transformou-se em uma área privilegiada para a implantação de meios para o escoamento da produção mineral. 
Figura 5. Decomposição da Variação do Emprego Formal em Mariana (MG) entre 2014 e 2016: componentes Nacional, Estrutural e Diferencial

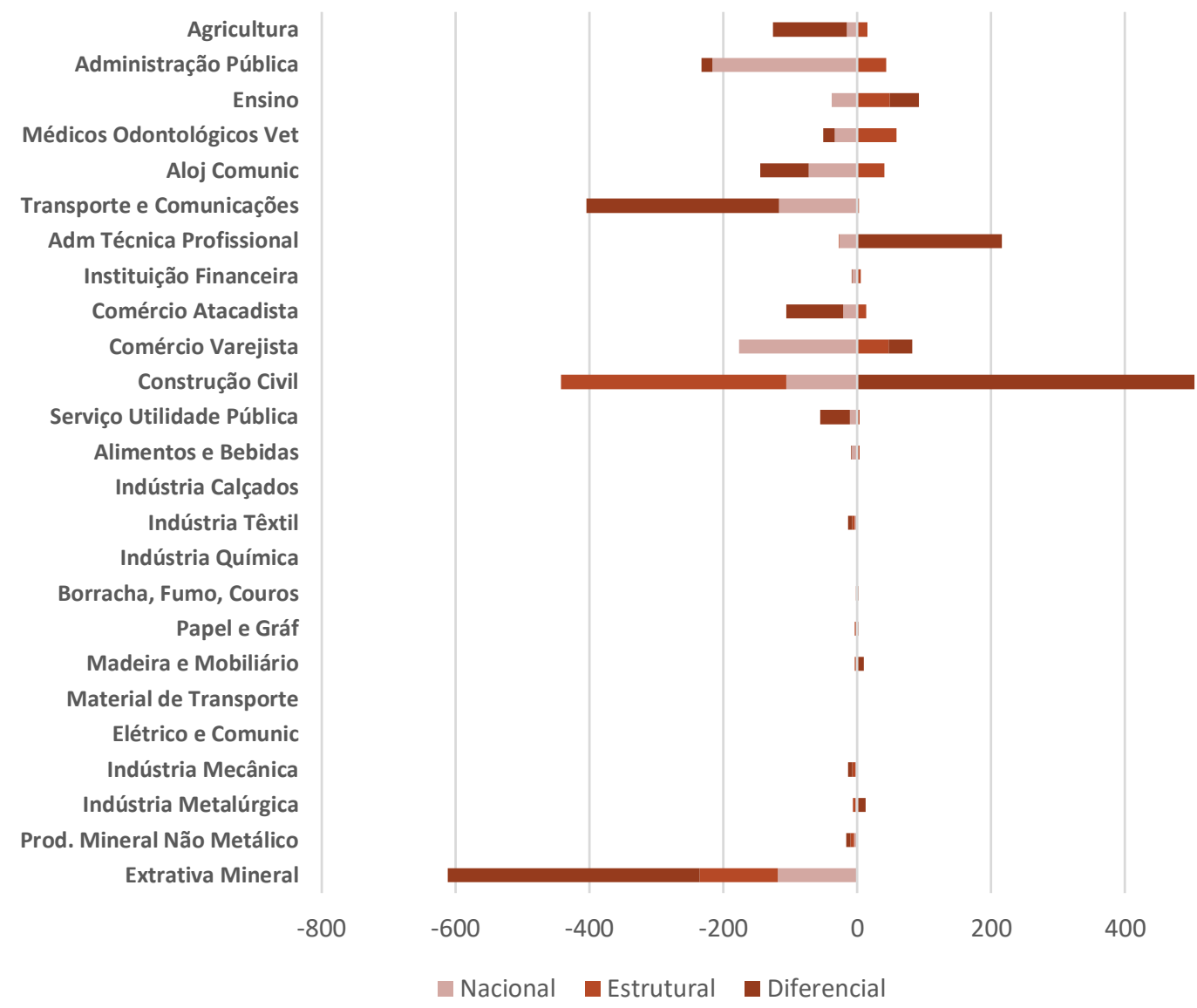

600

Fonte: Elaboração Própria a partir dos Dados da RAIS/TEM (2018).

Ainda na fase inicial de consolidação industrial no Vale do Rio Doce ${ }^{4}$, o comércio era caracterizado como varejista, importando produtos industrializados e manufaturados e exportando produtos alimentícios. A centralização de algumas atividades industriais, relacionadas às novas demandas, fez surgir novos serviços e modalidades de comércio. A instalação das indústrias de bens de produção intermediários como as siderúrgicas Usiminas, em Ipatinga, e a Acesita, em Timóteo iniciaram a longa relação entre essa região e a produção de aço, contribuindo para a alteração da dinâmica e estrutural de alguns municípios da região.

No caso de Mariana, a especialização produtiva no setor extrativista mineral e, ainda, o baixo dinamismo do setor de serviços são fatores que comprometem a capacidade de recuperação pós-choque. Se sua principal especialização industrial desacelerar, ela terá muito menos margem para direcionar seu produto para outros

4 Composta pelos municípios de Ipatinga, Timóteo, Coronel Fabriciano, Caratinga, Belo Oriente e Santana do Paraíso, o Vale do Aço é formado por um conjunto de municípios localizados às margens do Rio Doce no leste do estado de Minas Gerais. 
setores, e será menos resistente em fornecer alguma medida de amortecimento frente a uma contração econômica.

\section{Políticas de Indução Setorial e Projetos de Diversificação Econômica - Alternativas Possíveis}

Uma das características fundamentais da resiliência é a capacidade de lidar com incertezas, mudanças e surpresas por meio da adaptação, da aprendizagem e da auto-organização frente a um conjunto de novas possibilidades (Buschbacher, 2014). De acordo com este autor, são características fundamentais à resiliência: i) processos e características estruturais que contribuem para a flexibilidade, a variabilidade de experiências, comunicação e aprendizagem; ii) sistemas que apresentam maior diversidade têm maior resiliência frente aos que maximizam a produtividade de apenas um benefício; iii) reservas de recursos e estoques de capital (financeiro, natural, humano, social e fabricado) permitem que o sistema se recupere após as perturbações; iv) o capital social, a liderança e a confiança contribuem para resiliência, assim como as instituições, as formas de organização social e de aprendizado em estrutura modular (redes descentralizadas têm maior resiliência que sistemas centralizados).

Na literatura internacional, o caso de Pittsburgh (nos Estados Unidos) é bastante emblemático para mostrar a importância da região se reinventar a partir dos seus atributos no sentido de aumentar a sua capacidade de resiliência frente aos choques e situações adversas. Prejudicada pelo surgimento de novas regiões produtoras de aço nos Estados Unidos e também da indústria siderúrgica global, Pittsburgh passou a ser vista como uma região de declínio deste tipo de produção e um local improvável para configurar um cluster de fornecedores intermediários para esta indústria5. Segundo Treado (2009), o legado adquirido com a indústria siderúrgica fez com que a cidade se reinventasse.

A partir do resgate dos elementos-chave da sua base industrial tradicional, favorecido pela sua localização estratégica, pela proximidade com regiões diversificadas, habilidade técnica e expertise regional; além dos incentivos à geração de conhecimento (associados ao investimento em ciência e tecnologia e aprimoramento da interação entre universidades e empresas), Pittsburgh continuou sendo o headquarter das grandes empresas do setor siderúrgico (tal como a Mitsubishi-Hitachi), mesmo após ter perdido participação na produção de aço.

A capacidade de reconversão econômica desta localidade se deu a partir da sua transição como produtora de aço para constituir uma região de desenvolvimento de tecnologia para o setor siderúrgico. Este cluster se beneficiou da reputação na compreensão da metalurgia e tecnologia na fabricação de aço e também como centro para engenharia de materiais. Ademais, sua localização para acessar fornecedores secundários (por contar com grandes construtores especializados), a centralidade de Pittsburgh no quesito 'aço' e no fornecimento de equipamentos, a

\footnotetext{
5 O trabalho de Dawley et al. (2008) também traz uma interessante análise sobre a reconfiguração da indústria siderúrgica (produção, empresas e impactos) no Norte da Inglaterra e no sul da Polônia, chamando a atenção para a capacidade de reconversão destas regiões. Para outros exemplos de cidades que se transformaram e se reconverteram economicamente após o declínio da sua atividade principal, consultar o segundo capítulo do trabalho de Silva (2018)
} 
capacidade de gerar empregos com alto salário e qualificado, contribuindo para o resgate econômico local.

Guardadas as especificidades de cada caso, é importante destacar que o grau de complexidade da economia de Minas Gerais reflete diretamente na capacidade das regiões do Estado reagirem aos choques adversos. No documento elaborado pelo Governo mineiro em 2015, intitulado 'Plano Mineiro de Desenvolvimento Integrado (2016-2027)' foi destacado que a consolidação industrial mineira nos anos 1970 foi importante, mas o Estado não foi capaz de acompanhar as transformações na economia mundial ocorridas nas décadas seguintes.

De acordo com este documento, uma característica marcante foi a disseminação da chamada "Economia do Conhecimento", associada à ocorrência de uma revolução tecnológica, na qual o conhecimento, a ciência e a tecnologia assumiram papel central na dinâmica econômica. No entanto, o trabalho revela que Minas Gerais não conseguiu, nestas últimas décadas, apontar sua indústria para este novo padrão, a não ser em casos isolados (notadamente na Região Metropolitana de Belo Horizonte e no Sul do Estado), o que revela a sua fragilidade estrutural, determinada pelo crescente peso da minero-metalurgia e da indústria tradicional, ambas de baixa-média intensidade tecnológica.

Os indicadores de resiliência calculados, de certa forma, refletem esta situação. A maior vulnerabilidade do setor produtivo é vista não só em Mariana, mas em outras localidades com perfis semelhantes, que sempre se mostram fragilizadas quando da eclosão de choques que perturbem a dinâmica econômica desses municípios. Pelas características gerais destacadas, tal vulnerabilidade está associada à baixa diversificação produtiva e às poucas alternativas de geração de emprego e renda que independam mais do setor motriz e da dinâmica do ciclo econômico.

Em Mariana, gerar condições para ampliar a capacidade de resiliência econômica passa, primeiramente, por ampliar a capacidade das famílias e empresas diversificarem suas fontes de renda, investirem nas relações sociais, manterem reservas de capital de diferentes tipos e desenvolverem competências de aprendizagem e de adaptação. Para Buschbacher (2014), essas medidas não eliminam as vulnerabilidades que vêm de outras escalas do sistema (como uma crise financeira recente ou o rompimento da Barragem de Fundão), mas, provavelmente, aquela com maior resiliência tem mais chance de se recuperar.

Essas ações passam, por exemplo, por uma mudança no uso dos recursos da CFEM pelas administrações municipais. Essa contribuição é um instrumento de grande importância para atenuar as externalidades negativas da atividade mineradora e, se bem aplicada, pode contribuir para a melhoria da equidade entre as gerações quanto a distribuição dos benefícios da extração mineral. No entanto, a falta de uma regulamentação específica que permita monitorar o gasto destes recursos e a falta de transparência ainda dificulta averiguar como essa contribuição tem sido usada nos municípios arrecadadores (GONÇALVES, 2014). Dessa forma, a dinâmica econômica dos municípios mineradores, sem que haja estímulos à diversificação produtiva via mecanismos indutores (principalmente por parte das políticas públicas), tende a favorecer e a reforçar grupos e localidades que são hierárquica e financeiramente mais fortes.

Tanto Gunderson e Holling (2002) quanto Buschbacher (2014) admitem que grande parte da capacidade de adaptação e reconversão virá de escalas menores do 
sistema - atores individuais e iniciativas locais testando e demonstrando alternativas. Mas o sistema precisará, também, de mecanismos para disseminar e replicar pequenos sucessos. Além disso, o contexto institucional e os processos que acontecem nas macroescalas do sistema devem criar um ambiente adequado para explorar as novas potencialidades e replicá-las no local. As soluções devem ser buscadas em todos os níveis (indivíduos, comunidades e no âmbito governamental).

Existe um relativo consenso na literatura econômica sobre a importância da diversificação produtiva como uma alternativa para melhorar a capacidade de resiliência e reconversão econômica regional. Desrochers (2001) remete à obra seminal de Jane Jacobs (1969) ${ }^{6}$ para destacar que a cidade diversificada tende a facilitar a transferência de know-how de uma área da indústria para outras que não estão relacionadas com os seus produtos finais. De acordo com o autor, ao oferecer um maior número e uma variedade de problemas a serem resolvidos, bem como um conjunto mais amplo de conhecimento especializado e outros recursos, uma cidade diversificada só pode aumentar as probabilidades de novas combinações e, de forma, estimular a criatividade dos indivíduos e empresas.

É cada vez mais reconhecida a importância da economia do conhecimento no âmbito dos sistemas regionais de inovação ${ }^{7}$ como uma estratégias de indução do desenvolvimento regional a partir do estímulo às atividades inovadoras e da melhoria dos canais de informação para fazer frente a uma economia cada vez mais globalizada. De acordo com Asheim et al. (2011), os sistemas regionais de inovação se integram no sistema global de inovação e seus agentes (multinacionais e acordos internacionais); ao sistema nacional de inovação (infraestrutura, instituições, sistema educacional, financiamento, sistema de pesquisa e desenvolvimento, governança), para a geração de transbordamentos científicos e tecnológicos regionais.

Neste contexto, as universidades e centros de pesquisa tem um papel central, permitindo desenvolver o conhecimento para aplicação comercial, aumentando a capacidade inovadora das empresas industriais existentes e melhorando sua competitividade global (BENNEWORTH, 2009) ${ }^{8}$. De acordo com este autor, o aumento das diversas demandas regionais faz com que as universidades aproveitem a sua base de conhecimento acadêmico, promovendo parcerias baseadas na pesquisa universidade-indústria e estimulando o empreendedorismo intensivo em conhecimento, impulsionando novos processos de aprendizagem institucionais.

No caso de Mariana, o papel das instituições de ensino, em especial, técnico e superior teve e terá um papel fundamental para se repensar a paisagem econômica do município. A Universidade Federal de Ouro Preto (UFOP) é considerada uma referência na formação de recursos humanos em diversas áreas do conhecimento, contando com cursos de graduação e pós-graduação, muitos deles vinculados às

\footnotetext{
${ }^{6}$ O livro a que o autor faz referência chama-se: "A economia das cidades", publicado em 1969.

7 Para detalhes sobre as características de um sistema regional de inovação, ver Cooke (1998, 2001).

${ }^{8}$ Benneworth (2009) traz um estudo de caso do papel e envolvimento da Universidade de Lund no sistema regional de inovação no sul da Suécia, na região de Scania. Embora esta universidade tenha sido considerada como uma instituição de ensino e pesquisa tradicional e relatividade independente, nas últimas décadas, aumentou a sua interação com empresas industriais, principalmente após o declínio da engenharia pesada (nos anos 1970 e 1980). Atualmente, a Scania é considerada uma região de alta tecnologia, especializada em ciência da vida e tecnologia da informação e comunicação (TIC), impulsionada pela maior interação com a Universidade de Lund.
} 
pesquisas alinhadas com as especialidades econômicas da região (engenharia de Minas, Metalúrgica, Geológica, Elétrica, Computação, Mecânica; Química, Biologia, Farmácia, Turismo ${ }^{9}$.

De acordo com Diniz (2001), essa condição contribui para um quesito que Florida (1995) considera como fundamental à manutenção de competitividade internacional das regiões frente à economia global: a presença de uma infraestrutura humana que favoreça a geração de conhecimento ${ }^{10}$. Em parceria com o setor privado, essas instituições poderiam se beneficiar de pesquisas, convênios para treinamento e qualificação de mão-de-obra, tal como no citado caso de Pittsburg.

As externalidades positivas geradas pela presença da UFOP, que historicamente tem acumulado pesquisas e expertise acadêmica voltada para o setor minerário, estabelecendo relações de cooperação com diversas empresas, é um importante canal para disseminação do conhecimento na área da mineração e nos setores correlatos, fortalecendo o ambiente inovativo ${ }^{11}$. Caberia, neste sentido, fortalecer a atuação das Universidades (e os demais centros de ensino e pesquisa da região) a desenvolverem parcerias, ações e projetos conjuntos voltados para o entorno, ou seja, que busquem e implementem estratégias as quais conciliem o fortalecimento e a diversificação da renda e da estrutura produtiva e que contribuam com a disseminação de um ambiente institucional mais favorável às atividades inovadoras. Tais iniciativas também ajudariam a fixar uma parte da mão de obra especializada formada na região, cuja parcela significativa de alunos ingressos tem origem de Mariana, Ouro Preto e entorno.

Ainda, é importante aproveitar as "janelas de oportunidades" típicas da própria região dos Inconfidentes, rica em atributos naturais, históricos, culturais, turísticos e religiosos que podem ser mais valorizados, inclusive, como estratégia de preservação. As valorizações destes atributos transcendem a esfera econômica, abarcando também a dimensão social, da relação de pertencimento e valorização do local, dos hábitos, das rotinas, dos costumes e da história dos próprios moradores. A abertura de novas janelas de oportunidades que favoreçam a troca de conhecimentos tácitos e acumulados, que preservem a memória local e, ainda assim, possibilitem a geração de ganhos econômicos, certamente, são fatores importantes para aumentar a capacidade de resiliência e reconversão produtiva de Mariana.

Por isso, as políticas de estímulo à implantação de novas empresas (como se tem pensado no âmbito do "Novo Distrito Industrial”) devem ser cautelosas quanto ao perfil das empresas ingressas. A atração majoritária de empresas que estejam fortemente correlacionadas às mineradoras, pode ter pouco impacto para ampliar a reconversão econômica marianense diante de novos choques. Discutir iniciativas e projetos que trabalhem a perspectiva de "novidade regional" pode ser mais positivo no contexto de estruturas econômicas regionais abrangendo atividades distintas, mas relacionadas, que possam absorver a mão de obra local e o seu conhecimento tácito e adquirido e que possam oferecer condições para ampliar a interação e a

\footnotetext{
${ }^{9}$ Além dos 38 cursos de graduação presencial e 4 à distância, a UFOP tem 22 programas de mestrado acadêmico; 13 de doutorado e 7 de mestrados profissionalizantes, afora especializações. O município de Mariana conta com outras instituições de ensino superior como a Faculdade de Mariana (FAMA); a UNIPAC, o ADJETIVO CETEP; além de ensino técnico do SENAI - FIEMG.

${ }^{10}$ FLORIDA, Richard. Toward the learning region. Futures, London, v. 27, n. 5, p. 527-536, June 1995.

${ }^{11}$ Sobre o papel da UFOP no desenvolvimento do setor minerário brasileiro, ver (SANTOS, 2009).
} 
inovação, além da capacidade de desenvolver atividades econômicas até então menos exploradas.

A partir do estudo das características estruturais e identificando as restrições que limitam a sua capacidade de reconversão econômica, a compreensão da dinâmica dos setores importantes para a geração de emprego e renda de Mariana se faz importante, partindo das suas potencialidades turísticas, patrimoniais, culturais e institucionais locais. Silva et al. (2017) sintetizam algumas janelas de oportunidades em atividades que façam convergir o conhecimento formal (adquirido) - via universidade e instituições de pesquisa com outros tipos de instituições (formais e informais), que atuam junto à população local, possibilitando a disseminação de vários tipos de conhecimentos e em vários níveis. Dentre as principais atividades levantadas pelas autoras, destaca-se o segmento de agricultura familiar, no qual o estímulo de práticas agrícolas mais complexas e pluriativas poderiam fazer esse segmento mais participativo e competitivo dentro da economia local. Além disso, o estreitamento das relações entre os produtores rurais com a UFOP, possibilitaria a melhora na organização da produção e na definição de estratégias para comercialização dos produtos, exposição e participação de eventos e feiras no município ou em outros mercados.

O segmento de artesanato tem a possibilidade de aproveitamento de grande parte do contingente local, desde que se torne mais organizados e menos pulverizados. Pode também ser capaz de atrair e reter os turistas a partir da consolidação de nichos competitivos, com mercados de produtos artesanais de maior valor agregado (café; queijos finos; azeites, etc). Na construção civil, alimentação e mobiliário também apresentam potenciais para diversificação de renda e geração de emprego no município, criando oportunidades de se trilhar uma nova trajetória de reconversão econômica de Mariana, a partir do aumento na participação de outros setores do produto interno municipal (SILVA et al., 2017).

Por fim, um dos setores identificado como estratégico para as políticas de indução é a atividade turística. Mariana (assim como sua vizinha Ouro Preto), é uma cidade histórica que retrata o período aurífero na região das minas no século XVIII. Por possuírem tais características, essas cidades recebem considerável número de turistas que, de uma maneira geral, estão interessados no turismo cultural, segmento turístico caracterizado pela "vivência do conjunto de elementos significativos do patrimônio histórico e cultural e dos eventos culturais, valorizando e promovendo os bens materiais e imateriais da cultura" (VIANNA e SILVA, 2013).

A atividade turística não se restringe apenas aos impactos econômicos, mas abre possibilidade de trabalhar com várias abordagens (relacionadas ao meio ambiente, ecologia, patrimônio histórico-cultural, empoderamento de grupos marginalizados, sustentabilidade); além de permitir relações mais intensas de pertencimento da população local com a sua história. Vianna e Silva (2013) destacam o caso do patrimônio cultural, que ajuda a reforçar os aspectos valorativos e sua preservação material, que é próprio do turismo cultural.

Mariana tem atributos e vantagens passíveis de gerar externalidades positivas para aprimorar o desenvolvimento deste setor, inclusive, utilizando de complementariedade com outros (por exemplo, conjugando os incentivos ao desenvolvimento do setor de turismo com agricultura, via incentivo ao turismo rural). Dadas as características do turismo regional (tipicamente cultural), acredita-se que o 
segmento das atividades recreativas e desportivas poderia assumir um papel mais significativo na geração de emprego e renda Vianna e Silva (2013) . Segundo estes autores, para isso, se faz necessária a adoção de políticas públicas que priorizem a qualificação e o aperfeiçoamento da mão de obra, assim como proponham uma maior integração das comunidades locais com o conhecimento e a valorização do patrimônio existente.

O estímulo a essa alternativa, conjugada às ações que empreendam efeitos multiplicadores em outros setores, pode ser um caminho no sentido de pensar opções de diversificação produtiva, de endogenização da renda no município, enfim, alternativas que permitam, a partir do desastre ocorrido em Mariana, atrair outros investimentos.

\section{Considerações Finais}

Com enfoque econômico voltado para a discussão dos entraves de um município tipicamente minerador frente à sua baixa capacidade de resiliência e reconversão aos choques adversos, este artigo apoiou-se, teoricamente, em elementos da literatura de desenvolvimento econômico, da geografia econômica e da economia regional para analisar as características estruturais e, ao mesmo tempo, contemporâneas de Mariana (MG). As medidas de aferição sugeridas (via indicador de resistência e recuperação baseado em Martin et al. 2016 e em análise de shift share) tornaram possível identificar que Mariana e os principais municípios especializados na atividade minerária (Ipatinga, Governador Valadares, Timóteo e Caratinga), que foram bastante atingidos pela conjuntura econômica interna e externa recentes, além do rompimento da barragem do Fundão.

O foco de qualquer estratégia de indução ao desenvolvimento socioeconômico não se esgota na retomada das atividades da indústria extrativa mineral no município, mas, sim, no entendimento de como Mariana poderá sair deste modelo de acumulação excludente para outro, menos dependente da mineração e mais sustentável, com mais diversidade econômica, mais empreendedorismo, com melhoria da qualidade dos negócios locais e dos empregos gerados por eles. Neste contexto, as universidades, os institutos federais e os centros de pesquisa são cada vez mais importantes para potencializar a capacidade inovadora regional, estimulando o conhecimento local, desenvolvendo e disseminando ciência e tecnologia; técnicas mais sustentáveis para a atividade produtiva, serviços com maior complexidade e valor agregado, a conformação de capital social mais bem qualificado, com potencial para estimular o revigoramento do processo criativo e novas possibilidades de diversificação produtiva.

Além de chamar a atenção para a importância de se repensar a atividade mineradora no contexto atual, o artigo defende que é imprescindível que sejam estimuladas e implementadas outras atividades produtivas que aumentem a capacidade de resiliência e recuperação econômica do município. Dentre estas estratégias destacam-se: maior interação universidade-empresa; a exploração sustentável de atividades que gerem emprego e internalize a renda gerada e aproveite dos atributos culturais, turísticos, patrimoniais, religiosos e históricos do município; a valorização do artesanato local e da agricultura familiar, entre outros.

Para além deste mapeamento de "janelas de oportunidades" setoriais que gera a possibilidade uma maior diversificação do produto, da renda e do emprego na região, reforça-se a necessidade de investir em educação básica, capacitação técnica; 
saúde, infraestrutura e saneamento básico, sem os quais não se pode pensar em um projeto de desenvolvimento de longo prazo para Mariana e seus distritos. Além do estímulo do setor público, das empresas privadas e das instituições de ensino e pesquisa, a estratégia de planejamento social e econômico de Mariana deverá abarcar a criação de oportunidades de voz e participação popular, com o intuito de mitigar o domínio das elites locais e capacitar grupos ainda pouco representados na sociedade.

O empoderamento da população pode levar à criação de novas formas locais de governança e à adoção de políticas que envolvam uma ampla gama de atores sociais mais sensíveis às questões como pobreza e desigualdade. O aumento da participação popular junto ao Poder Público na discussão de temas relevantes e das estratégias de planejamento municipal confere maior transparência e responsabilidade às ações locais e ajuda a restringir as oportunidades de corrupção, ou mesmo o risco de que um pequeno grupo privilegiado capture os retornos das políticas públicas.

Esse novo modelo deverá passar, necessariamente, pela valorização do capital social da região, resgatando a sua história, as pessoas, o pertencimento ao lugar, as tradições. $\mathrm{E}$, também, pela valorização das políticas de apoio e aproveitamento do rico patrimônio cultural e histórico para fins de promoção e acesso às atividades culturais, preservação da memória e da história local que priorizam a discussão de um modelo cuja dimensão econômica não se sobrepõe às demais, lógica contrária à da atividade mineradora.

Por fim, destaca-se que esta é uma agenda de pesquisa em aberto, que deve pautar-se pela incorporação de novos focos de análises. Uma das limitações deste artigo é o horizonte temporal ainda recente para se ter uma boa aferição do impacto econômico mais amplo dos choques pelas quais a economia marianense (e mineira) tem sofrido, o que poderá ser obtido com uma série mais longa de dados e a introdução de técnicas econométricas mais precisas para este fim. Além disso, é de fundamental importância incorporar à análise o papel da governança e da gestão local, como também das interações e parcerias possíveis entre empresas e instituições públicas e privadas, de modo a permitir a definição conjunta de estratégias de desenvolvimento.

\section{Referências}

ANGULO, A.; MUR, J.; TRIVEZ, J. Measuring resilience to economic shocks: an application to Spain. Annals of Regional Science, v.60, n.2, p. 349-373, 2018.

ASHEIM, B. T.; SMITH, H.; OUGHTON, C. Regional Innovation Systems: Theory, empirics and policy. Regional Studies, v. 45, n. 7, p. 875-892, 2011.

BENNEWORTH, P., COENEN, L.; MOODYSSON, J.; ASHEIM, B. Exploring the Multiple Roles of Lund University in Strengthening Scania's Regional Innovation System: Towards Institutional Learning?, European Planning Studies, 17:11, 16451664, 2009. 
BUSCHBACHER, R. A teoria da resiliência e os sistemas socioecológicos: como se preparar para um futuro imprevisível? Boletim Regional, Urbano e Ambiental (IPEA) $\mathrm{N}^{\circ} 09$ - janeiro a junho de 2014.

COOKE, P. Regional Innovation Systems, Clusters, and the Knowledge Economy. Industrial and Corporate Change, v. 10, n. 4, p. 44-45, 2001.

COOKE, P. Introduction: origins of the concept. In: BRACZYC, H.; COOKE, P.; HIDERNREICH, M. (Eds.). Regional Innovation Systems. London: UCL Press, 1998. p. $2-25$.

CHRISTOPHERSON, S., MICHIE, J., TYLER, P. Regional Resilience: theoretical and empirical perspectives. Cambridge Journal of Regions, Economy and Society, vol. 3, p. 3-10, 2010.

DAWLEY, S; PIKE, A; TOMANEY, J. Towards the resilient region? Local Economy, v. 25 , n. 8, p. 650-667, 2010.

DAWLEY, S.; STENNING A.; PIKE,A.; Mapping Corporations, Connecting Communities, European Urban and Regional Studies, Vol. 15, No. 3, 265-287, 2008 DESROCHERS, P. Urban Diversity, Human Creativity, and Technological Innovation. Mimeo. 2001. Disponível em:

https://www.researchgate.net/publication/2386759_Urban_Diversity_Human_Creati vity_and_Technology_Combination. Acesso em: ago. 2016.

DEPARTAMENTO NACIONAL DE PRODUÇÃO MINERAL (DNPM). Anuário Mineral Brasileiro: Principais Substâncias Metálicas / Coord. Geral Wagner Fernandes Pinheiro, Osvaldo Barbosa Ferreira Filho, Carlos Augusto Ramos Neves. Brasília: DNPM, 2016.

DEPARTAMENTO NACIONAL DE PRODUÇÃO MINERAL (DNPM). Maiores arrecadadores de CFEM, 2016. Disponível em:

https://sistemas.dnpm.gov.br/arrecadacao/extra/Relatorios/cfem/maiores_arrecada dores.aspx. Acesso em: 14 jul. 2017

DINIZ, C. C. O papel das inovações e das instituições no desenvolvimento local. In: ENCONTRO NACIONAL DE ECONOMIA, 2001, Anais. Salvador:ANPEC, 2001.

DI CARO, P.; FRATESI, U. Regional determinants of economic resilience. Annals of Regional Science, Vol. 60, No. 2, p. 235-240, 2018

DUBÉ, J. POLÈSE, M. Resilience Revisited: Assessing the Impact of the 2007-09 Recession on 83 Canadian Regions with Accompanying Thoughts on an Elusive Concept. Regional Studies, Vol. 50, No. 4, 615-628, 2014. 
ENRíQUEZ, Maria Amélia Rodrigues da Silva. Maldição ou dádiva? os dilemas do desenvolvimento sustentável a partir de uma base mineira. 2007. $449 \mathrm{f}$. Tese (Doutorado em Desenvolvimento Sustentável) - Universidade de Brasília, 2007.

EVENHUIS, E. New directions in researching regional economic resilience and adaptation. Geography Compass, v. 11, n. 11, p. 1-15, 2017.

FINGLETON, B; GARRETSEN, H; MARTIN, R. Recessionary shocks and regional employment: evidence on the resilience of UK regions. Journal of Regional Science, v. 52, n. 1, p. 109-133, 2012.

FJP (2017). Produto Interno Bruto dos Municípios de Minas Gerais: 2015/ Fundação João Pinheiro, Diretoria de Estatística e Informações. - Belo Horizonte: FJP, 2017.

FOSTER, K A. A Case Study Approach to Understanding Regional Resilience. Institute of Urban\& Regional Development, 2007.

GIANNAKIS, E.; BRUGGEMAN, A. Economic crisis and regional resilience: Evidence from Greece. Papers in Regional Science, v. 96, n. 3, p. 451-476, 2017.

GONÇALVES, J.M. Desenvolvimento Local e Mineração: um estudo de caso dos municípios de Mariana e Ouro Preto a partir da Compensação Financeira pela Exploração de Recursos Minerais. Monografia apresentada para integralização do Curso de Ciências Econômicas - UFOP. Mariana, 2014.

GOVERNO DE MINAS GERAIS. Plano Mineiro de Desenvolvimento Integrado - 2016 a 2027. Desenvolvimento Econômico e Social Sustentável De Minas Gerais. Volume I. 2015. Disponível em https://www.almg.gov.br/export/sites/default/acompanhe/planejamento_orcament o_publico/pmdi/pmdi/2015/documentos/pmdi_2015_vol_I.pdf. Acesso em: maio 2017.

GOVERNO DE MINAS GERAIS Plataforma DATAVIVA Disponível em http://www.transparencia.mg.gov.br/. Acesso em: maio 2017.

GUNDERSON, L. H.; HOLLING, C. S.(Eds.); Resilience and adaptive cycles. In: Panarchy: understanding transformations in human and natural systems, Washington:Island Press, 2002.

HILL, E; WIAL, Ho; WOLMAN, H. Exploring regional economic resilience. Working Paper, Institute of Urban and Regional Development, 2008.

IBGE (2014) Instituto Brasileiro de Geografia e Estatística. Dados Populacionais de Mariana. Disponível em: <http://www.cens02010.ibge.gov.br>. Acesso: 19 maio 2017. 
INSTITUTO BRASILEIRO DE MINERAÇÃO (IBRAM). Informações sobre a economia mineral brasileira 2015. Brasília, 2015. Disponível em:

http://www.ibram.org.br/sites/1300/1382/00005836.pdf. Acesso em: jul. 2017.

LEMOS, M.B; DINIZ, C.C. Sistemas regionais de inovação: o caso de Minas Gerais. Nota Técnica 06/98 - Projeto de Pesquisa Globalização e Inovação Localizada: Experiências de Sistemas Locais no Âmbito do Mercosul e Proposições de Políticas de C\&T, 1998.

LEE, N. Grim down south? The determinants of unemployment increases in British cities in the 2008-2009 recession. Regional Studies. 2012.

MARTIN, R; SUNLEY, P; GARDINER, B; TYLER, P. How Regions React to Recessions: Resilience and the Role of Economic Structure, Regional Studies, 50:4, 561-585, 2016.

MARTIN, R. Regional economic resilience, hysteresis and recessionary shocks. Journal of Economic Geography, Volume 12, Issue 1, p. 1-32, 2012.

MYRDAL, Gunnar. Teoria Econômica e Regiões Subdesenvolvidas. ISEB. Ministério da Educação e Cultura. Rio de Janeiro, 1960.

PASSOS, F. L., COELHO, P., \& DIAS, A. (Des)territórios da mineração: planejamento territorial a partir do rompimento em Mariana, MG. Cadernos Metrópole, 19(38), 269-297. https://dx.doi.org/10.1590/2236-9996.2017-3811, 2017

PENDALL, R; FOSTER, K.; COWELL, M. Resilience and regions: building understanding of the metaphor. Cambridge Journal of Regions, Economy and Society, v. 3, n. 1, p. 71-84, 2010.

PIKE, A; DAWLEY, S; TOMANEY, J. Resilience, adaptation and adaptability. Cambridge Journal of Regions, Economy and Society, 2010.

PNUD, Ipea e FJP (2017) Atlas de Desenvolvimento Humano Municipal. Disponível em http://www.atlasbrasil.org.br/2013/pt/perfil_m/mariana_mg. Acesso: maio 2017.

RAY, D.M., et al. Economic shock and regional resilience: Continuity and Change in Canada's regional employment structure, 1987-2012. Environment and Planning A, vol.49, n.4, p. 952-973.

SANTOS, Ulisses Pereira dos. Ambiente Institucional e Inovação na Siderurgia de Minas Gerais. 2009. 140f. Dissertação de Mestrado em Economia do Centro de Desenvolvimento e Planejamento Regional da Universidade Federal de Minas Gerais, 2009.

SILVA, J. F. Da Especialização Produtiva ao Rompimento da Barragem de Fundão: uma Análise da Resiliência Econômica para o Município de Mariana/MG. Dissertação 
de Mestrado apresentada ao Programa de Pós Graduação em Economia Aplicada da UFOP (PPEA-UFOP). 2018.

SILVA, F. F.; SILVA, J. F.; ANDRADE, M. L. F. Indicadores Setoriais de Resiliência regional para Mariana (MG). Proposta de colaboração acadêmica BDMG, PPEAUFOP. Mariana, 2017. Mimeo.

SIMMIE, J; MARTIN, R. The economic resilience of regions: towards an evolutionary approach. Cambridge Journal of regions, economy and society, v. 3, n. 1, p. 27-43, 2010.

SOUZA, C.C.A.; VIANNA, R.M.; LEAL FILHO, R.S. Desigualdade nos territórios de desenvolvimento de Minas Gerais: período 2000 a 2013. Anais do XVII Seminário Sobre Economia Mineira. Vol.1, pags .560-585. 2016. Disponível em:

http://diamantina.cedeplar.ufmg.br/2016/anais_economia.html. Acesso: julho, 2017.

SUPERINTENDÊNCIA DE PLANEJAMENTO DE RECURSOS HÍDRICOS. Encarte Especial sobre a Bacia do Rio Doce e o Rompimento da Barragem em Mariana/MG, 2016. Disponível em:

http://arquivos.ana.gov.br/RioDoce/EncarteRioDoce_22_03_2016v2.pdf.Acesso: julho de 2017.

TUPY, Igor Santos; CROCCO, Marco; SILVA, Fernanda Faria. Resiliência e impactos regionais de crises financeiras: uma análise para os estados brasileiros - 2007/08. Economia e Sociedade, v. 27, n. 2, p. 607-636, 2018.

TUPY, I. S. Impactos Regionais de Crises Financeiras: Estudo sobre as respostas dos Estados Brasileiros à Crise Financeira Global. Dissertação (Mestrado em Economia). Belo Horizonte: Programa de Pós-Graduação em Economia, CEDEPLAR/ UFMG, 2015.

TREADO C. D. Pittsburgh's evolving steel legacy and the steel technology cluster, Cambridge Journal of Regions, Economy and Society 3, 105-120, 2010.

VIANNA, F.D.F.; SILVA, A.L. e Contribuições do Turismo às Economias de Ouro Preto e Mariana. Revista Turismo \& Desenvolvimento, v. 11, p. 1-24-24, 2013. 
Fernanda Faria Silva. Professora Adjunta do Programa de Pós-Graduação em Economia Aplicada, PPGEA/ICSA/UFOP. fernandaicsa@gmail.com

Jordana Ferreira da Silva. Doutoranda em Economia no CEDEPLAR/UFMG. jordanafsilvaufop@gmail.com

Igor Santos Tupy. Professor Adjunto do Departamento de Economia, DEE/UFV. igor.tupy@ufv.br

Como citar: SILVA, Fernanda Faria; SILVA, Jordana Ferreira da; TUPY, Igor Santos. Reflexões Sobre Resiliência Econômica Regional: o cenário pós-desastre de Mariana (MG). Redes, Santa Cruz do Sul, v. 24, n. 2, p. 29-55, maio 2019. ISSN 1982-6745. Disponível em: https://doi.org/10.17058/redes.v24i2.12974. 


\section{ANEXO}

Tabela A1. : Indicadores de resistência dos municípios selecionados (2013 a 2017)

\begin{tabular}{|c|c|c|c|c|c|c|c|c|c|c|c|c|c|c|c|c|}
\hline & \multicolumn{3}{|c|}{ Caratinga } & \multicolumn{3}{|c|}{ Governador Valadares } & \multicolumn{3}{|c|}{ Ipatinga } & \multicolumn{3}{|c|}{ Mariana } & \multicolumn{3}{|c|}{ Timóteo } & \\
\hline & $\operatorname{Res}_{2013}$ & $\operatorname{Res}_{2015}$ & $\operatorname{Res}_{2016}$ & $\operatorname{Res}_{2013}$ & $\operatorname{Res}_{2015}$ & $\operatorname{Res}_{2016}$ & $\operatorname{Res}_{2013}$ & $\operatorname{Res}_{2015}$ & $\operatorname{Res}_{2016}$ & $\operatorname{Res}_{2013}$ & $\operatorname{Res}_{2015}$ & $\operatorname{Res}_{2016}$ & $\operatorname{Res}_{2013}$ & $\operatorname{Res}_{2015}$ & $\operatorname{Res}_{2016}$ & Média \\
\hline $\begin{array}{l}\text { Extrativo } \\
\text { mineral }\end{array}$ & 0,82 & $-1,00$ & $-0,94$ & 0,88 & 0,90 & $-0,93$ & 0,92 & $-0,94$ & $-0,90$ & 0,83 & $-0,74$ & $-0,97$ & 1,00 & $-0,92$ & $-0,85$ & $-0,19$ \\
\hline $\begin{array}{l}\text { Indústria de } \\
\text { transformação }\end{array}$ & $-0,84$ & $-0,87$ & $-0,01$ & 0,90 & $-0,92$ & $-0,79$ & $-0,91$ & $-0,91$ & $-0,72$ & 1,24 & $-0,90$ & $-0,74$ & $-0,89$ & $-0,86$ & $-0,65$ & $-0,52$ \\
\hline $\begin{array}{l}\text { Serviços } \\
\text { Industriais de } \\
\text { Utilidade } \\
\text { Pública }\end{array}$ & $-0,63$ & $-0,86$ & 0,75 & 0,63 & $-0,84$ & $-0,76$ & $-0,67$ & $-0,88$ & $-0,80$ & 0,63 & $--*$ & $--*$ & $-0,25$ & $--*$ & $-0,52$ & $-0,35$ \\
\hline $\begin{array}{l}\text { Construção } \\
\text { Civil }\end{array}$ & 0,98 & $-0,96$ & $-0,92$ & 0,89 & $-0,98$ & $-0,98$ & 0,96 & $-0,97$ & $-0,95$ & 0,97 & $-0,97$ & $-0,93$ & 0,94 & $-0,98$ & $-0,95$ & $-0,32$ \\
\hline Comércio & $-2,69$ & $-2,83$ & $-0,56$ & $-2,01$ & $-0,78$ & $-0,64$ & $-2,67$ & $-0,87$ & $-0,74$ & $-1,93$ & $-0,87$ & $-0,60$ & 1,51 & $-0,80$ & $-0,59$ & $-1,14$ \\
\hline Serviços & $-0,78$ & 2,25 & 1,25 & $-1,54$ & $-1,25$ & $-0,62$ & $-1,30$ & $-0,67$ & $-0,40$ & $-1,73$ & $-0,30$ & $-1,90$ & $-6,30$ & $-0,84$ & $-3,41$ & $-1,17$ \\
\hline $\begin{array}{l}\text { Administração } \\
\text { Pública }\end{array}$ & $-1,88$ & $-0,56$ & $-0,04$ & 1,88 & $--*$ & $--*$ & 1,88 & $-0,56$ & $--*$ & $-1,88$ & $-0,56$ & $--*$ & $--*$ & $-1,44$ & $-1,88$ & $-0,50$ \\
\hline $\begin{array}{l}\text { Agropec } \\
\text { extração } \\
\text { vegetal, caça e } \\
\text { pesca }\end{array}$ & 1,23 & $-2,50$ & $-3,93$ & 1,25 & 1,04 & 0,00 & 1,46 & 1,36 & $--*$ & $-1,39$ & 1,51 & 3,55 & $-2,13$ & $-1,66$ & $-3,32$ & $-0,25$ \\
\hline
\end{tabular}

* O cálculo não foi possível em função de não ter tido novas neste setor no ano analisado.

Fonte: Cálculo e Tabulação própria a partir dos dados do CAGED. 